\title{
Potencial ecoturístico de paisagens simbólicas em territórios protegidos: reflexões a partir da Área de Proteção Ambiental da Região de Maracanã, São Luís - MA, Brasil
}

\author{
Ecotourism potential of symbolic landscapes in protected territories: \\ reflections on the Environmental Protection Area of the Maracanã Region, \\ São Luís - MA, Brasil

\section{Fabiana Pereira Correia ${ }^{\mathrm{a}}$ LuCiene CRistina Risso ${ }^{b}$}
${ }^{\text {a }}$ Doutoranda do Programa de Pós-Graduação em Geografia da Universidade Estadual Paulista "Júlio de Mesquita Filho" (Unesp), campus de Rio Claro.
E-mail: amopachamama@gmail.com

\begin{abstract}
b Docente da Universidade Estadual Paulista "Júlio de Mesquita Filho" (Unesp), campus de Ourinhos, vinculada ao Programa de Pós-Graduação em Geografia da Unesp, campus de Rio Claro.

E-mail: rissoluciene@gmail.com
\end{abstract}

\begin{abstract}
Este artigo expõe parte dos resultados de uma pesquisa de doutorado vinculada ao Programa de PósGraduação em Geografia da Universidade Estadual Paulista "Júlio de Mesquita Filho", campus de Rio Claro. A pesquisa está sendo realizada desde 2017 e, desde abril de 2018, recebe fomento da Fundação de Amparo à Pesquisa e ao Desenvolvimento Científico e Tecnológico do Maranhão. A problemática vincula-se ao campo da Geografia Humanista-Cultural Fenomenológica. O problema é relevante na medida em que considera o simbolismo das paisagens enquanto fator capaz de ampliar perspectivas relacionadas à conservação da natureza, tendo em vista o ecoturismo. O principal objetivo é refletir sobre o potencial ecoturístico de paisagens simbólicas em territórios protegidos, partindo da realidade da Área de Proteção Ambiental (APA) da Região de Maracanã. Os resultados foram obtidos através de levantamento bibliográfico, elaboração e aplicação de entrevistas semiestruturadas, participação em eventos nas comunidades e registro fotográfico. Conclui-se que paisagens simbólicas constituem fatores relevantes para o ecoturismo em territórios protegidos, especialmente em APAs, cujas principais características dizem respeito às relações diretas entre os humanos e as paisagens às quais suas vivências estão vinculadas.
\end{abstract}

Palavras-chave: geografia humanista-cultural, paisagem, ecoturismo, conservação.

\begin{abstract}
This article originates from part of the results of a doctorate research linked to the Geography Graduate Program of the São Paulo State University "Júlio de Mesquita Filho" (Unesp), Rio Claro campus. The research has been developed since 2017 and, since 2018, has been funded by the Fundação de Amparo à Pesquisa e ao Desenvolvimento Científico e Tecnológico do Maranhão (Fapema). The investigation is related to the field of the phenomenological Cultural-Humanistic Geography. The problem analyzed here is relevant insofar as it considers the symbolism of landscapes as a factor capable of expanding perspectives related to the conservation of nature, in view of ecotourism. The main goal is to reflect upon the ecotouristic potential of symbolic landscapes in protected territories based on the reality of the Environmental Protection Area (EPA) of the Maracanã Region. The results were obtained through a bibliographical compilation, preparation and application of semi structured interviews, participation in community events, and photographical registration. Symbolic landscapes are shown to be relevant factors for ecotourism in protected territories, especially APAs, whose main characteristics are associated with the direct relations between humans and the landscapes to which their experiences are connected.
\end{abstract}

Keywords: cultural-humanistic geography, landscape, ecotourism, conservation. 


\section{INTRODUÇÃO}

Paisagem, uma das categorias-chave da Geografia, pode ser interpretada enquanto unidade integrada de elementos naturais e culturais (materiais e imateriais) característicos de determinada porção do espaço geográfico. Seus aspectos culturais são intrinsecamente vinculados à vivência humana na Terra, que inclui a dimensão simbólica, bem como ao trabalho que indivíduos e grupos executam para adaptar os sistemas ambientais às suas necessidades e vontades.

Nos estudos geográficos sobre a paisagem, destaca-se a abordagem cultural, uma das matrizes da Geografia Humanista. No âmbito dessa perspectiva teórico-metodológica, situa-se a linha de pensamento representada por Denis Cosgrove (1998, 2004), que investiga a paisagem como ente geográfico essencialmente simbólico, resultado da produção social, cujas formas e características refletem ideologias. Assim, as paisagens são entes impregnados de significados e, portanto, "contam histórias" acerca dos lugares que integram. Aos elementos da paisagem e a ela própria são atribuídos significados humanos, o que lhes confere identidade simbólica.

Sob esse viés, o presente artigo enfatiza a paisagem simbólica ${ }^{1}$ enquanto fator potencialmente relevante ao desenvolvimento do ecoturismo em territórios protegidos, tendo em vista a realidade da Área de Proteção Ambiental (APA) da Região de Maracanã, localizada na zona rural do município de São Luís, capital do estado do Maranhão. Dentre as paisagens simbólicas da APA, destaca-se a associada ao Bumba-meu-Boi do Maracanã, manifestação da cultura popular integrante do Complexo Cultural do Bumba-meu-Boi do Maranhão, bem como a associada ao Tambor de Crioula do Maranhão, ambos registrados no Instituto do Patrimônio Histórico e Artístico Nacional como patrimônios culturais imateriais do Brasil.

Cumpre notar que no decreto de criação da APA há destaque para o ecoturismo, o valor cultural e histórico da região, a relevância das manifestações populares e a salvaguarda do patrimônio natural e cultural. Assim, os sistemas ambientais, em que se destacam

1 Coadunando com as ideias expressas pelo referencial teórico, entende-se que toda paisagem é essencialmente simbólica. A opção pela adjetivação justifica-se pela necessidade de ratificar essa característica das paisagens. a fauna; os corpos hídricos; as áreas de preservação permanente (APP); as áreas construídas; as manifestações culturais, dentre as quais a Festa da Juçara, a Festa de Santos Reis, as Ladainhas, o Bumba-meuBoi do Maracanã e o Tambor de Crioula, constituem elementos-chave nas paisagens simbólicas da APA, realidade positiva quando se pretende desenvolver o ecoturismo no território protegido.

$\mathrm{O}$ ecoturismo situa-se entre as possibilidades de redução dos impactos negativos da economia humana sobre os sistemas ambientais, portanto se destaca como atividade econômica relevante quando se atenta à urgente necessidade de conservação da natureza. Não se pode negar que o setor integra o rol das estratégias utilizadas na reprodução do capital; entretanto, convém lembrar que os princípios do ecoturismo são orientados pelo reconhecimento de que a sustentabilidade ambiental é imprescindível à manutenção da vida na Terra. Também cabe lembrar que, além dos benefícios ambientais, o ecoturismo representa a possibilidade de inclusão social.

Apreender o simbolismo da paisagem em território protegido, considerando seu potencial ecoturístico, se justifica pela oportunidade de suscitar reflexões e ações, tanto do Poder Público quanto da sociedade civil, acerca dos possíveis benefícios oriundos da articulação entre esses três aspectos fundamentais da contemporaneidade: paisagem, ecoturismo e conservação da natureza.

No intuito de facilitar a leitura, o texto foi organizado em tópicos, os quais detalham os objetivos da abordagem, a metodologia utilizada, a fundamentação teórica e os resultados alcançados.

\section{OBjetivos}

O objetivo geral desta abordagem é refletir acerca do potencial ecoturístico de paisagens simbólicas no contexto de territórios protegidos. Como desdobramento desse objetivo, busca-se: contribuir com a ampliação de conhecimento acerca dos aspectos simbólicos das paisagens da APA da Região de Maracanã; chamar atenção para a relevância da apreensão do simbolismo das paisagens no desenvolvimento do ecoturismo na APA; propor que as paisagens simbólicas da APA sejam reconhecidas pelo Poder Público e pela coletividade como patrimônios culturais. 


\section{Metodologia}

Considerando a especificidade da abordagem, as orientações de Cosgrove (2004, p. 103) serviram de guia para a metodologia adotada: "revelar os significados na paisagem cultural exige a habilidade imaginativa de entrar no mundo dos outros de maneira autoconsciente e, então, representar essa paisagem num nível no qual seus significados possam ser expostos e refletidos".

A consecução dos resultados foi possível por meio dos seguintes procedimentos metodológicos: levantamento e revisão bibliográfica, elaboração e aplicação de entrevistas semiestruturadas, participação em eventos nas comunidades e registro fotográfico em smartphone.

\section{FundamentaÇão teóRICA}

\section{Paisagem, essência geográfica do mundo simbólico}

Paisagem, assim como outras palavras criadas pelo ser humano para designar componentes do mundo, pode ser interpretada sob diversos pontos de vista, tendo destaque os significados que a vinculam à Arte e à Geografia. Na história da Geografia, Mendonça (2001, p. 46) lembra que "a noção de paisagem originou-se com os geógrafos alemães no século XIX e o seu conceito é de natureza sobretudo fisionômica".

Para Cosgrove (1998, p. 1), a paisagem transcende aspectos fisionômicos; ela representa um modo de ver: "the landscape idea represents a way of seeing". $\mathrm{O}$ autor ratifica seu posicionamento ao afirmar que "a paisagem, de fato, é uma 'maneira de ver', uma maneira de compor e harmonizar o mundo externo em uma 'cena', em uma unidade visual” (COSGROVE, 2004, p. 98).

Estudos acerca das paisagens geralmente evidenciam que elas consistem em unidades compostas por diversos elementos, podendo inclusive ser subdivididas. Entretanto, ao apreendê-las sob a perspectiva geográfica, "estamos interessados naquela parte da paisagem que nos diz respeito como seres humanos porque nós somos parte dela, vivemos com ela, somos limitados por ela e a modificamos" (SAUER, 2004, p. 29).

Parte-se do pressuposto de que "todas as paisagens são simbólicas" (RAPOPORT, 1982 apud COSGROVE, 2004, p. 106) e "possuem significados simbólicos porque são o produto da apropriação e transformação do [...] ambiente pelo homem" (COSGROVE, 2004, p. 108). No mesmo sentido,
Sautter (1979 apud BONNEMAISON, 2002) indica que a paisagem é, simultaneamente, prolongamento e reflexo de uma sociedade.

Autores como Nogué (2016) apreendem a paisagem enquanto construção social que vai além daquilo que os olhos conseguem enxergar; portanto, chamam atenção para o seu simbolismo. Sob esse ponto de vista, ratifica-se que as paisagens são compostas por lugares: "centros de significados e [...] símbolos que expressam pensamentos, ideias e emoções" (NOGUÉ, 2016, p. 12). Ao discorrer sobre paisagem, Besse (2014, p. 79) esclarece: "a paisagem é da ordem do sentir. Ela é participação e prolongamento de uma atmosfera, de uma ambiência".

As considerações de Bertrand (2004) auxiliam na compreensão do que se entende por paisagem, considerando sua dimensão cultural, a qual vai ao encontro da concepção defendida por Cosgrove (1998, 2004).

A paisagem não é a simples adição de elementos geográficos disparatados. É, em [...] determinada porção do espaço, o resultado da combinação dinâmica, portanto instável, de elementos físicos, biológicos e antrópicos que, reagindo dialeticamente uns sobre os outros, fazem da paisagem um conjunto único e indissociável, em perpétua evolução. (BERTRAND, 2004, p. 141)

No mesmo sentido conflui o pensamento de Mendonça (2001, p. 47), especialmente ao afirmar que a ideia de paisagem desenvolvida principalmente pelos alemães (landschaft) "não é entendida somente como o meio natural ou os aspectos físicos do planeta, mas também incorpora o homem através de suas ações ao seu conjunto de elementos". Assim, a afirmação conduz à ratificação do caráter cultural, portanto simbólico, da paisagem, essa parcela significativa do espaço geográfico.

Cosgrove (2004) chama atenção para a relevância da obra de Carl Sauer, tendo em vista que sua base teórica originou uma escola de geografia da paisagem (escola de Berkeley), cuja ênfase recai sobre o papel do homem na transformação da face da Terra. Ao pensar na paisagem enquanto entidade cujo cerne se origina do "entrelaçamento" entre os seres humanos e o planeta, é possível perceber, conforme Cosgrove (2004, p. 120-121), que ela "está repleta de símbolos [...] e de seu significado simbólico".

Berque (2004, p. 84, grifo do autor) defende que a paisagem é, simultaneamente, marca e matriz: "A paisagem é uma marca, pois expressa uma civilização, mas é também uma matriz porque participa dos esquemas de percepção, 
de concepção e de ação - ou seja, da cultura - que canalizam, em certo sentido, a relação de uma sociedade com o espaço e com a natureza".

Tendo em vista a interpretação cultural da paisagem, entende-se cultura como "sistema de representação simbólica [...] uma "visão de mundo"" (BONNEMAISON, 2002, p. 86). Na mesma obra, o autor reforça a ideia de que o contato entre uma sociedade e suas paisagens está repleto de afetividade, exprimindo uma relação cultural.

Holzer (1997, p. 81) destaca que o termo paisagem permite à Geografia "colocar-se como uma das ciências das essências nos moldes propostos pela fenomenologia". Sob o mesmo viés, Corrêa e Rosendahl (2004) afirmam que a paisagem pode ser vista como expressão humana intencional constituída por muitas camadas de significação. A assertiva ratifica a dimensão simbólica da paisagem, deixando clara a centralidade da cultura na "leitura" e compreensão dessa parcela significativa do espaço geográfico.

Ao refletir sobre o sentido simbólico da paisagem, Risso (2008, p. 72-73) reforça que ela tem um significado para cada pessoa ou grupo, pois "as pessoas atribuem valores e significados diferentes às suas paisagens, traduzidos em sentimentos de enraizamento ou desapego aos lugares". O posicionamento da autora ratifica a necessidade de enfoques capazes de contribuir com a valorização dos aspectos simbólicos inerentes às relações entre comunidades tradicionais e paisagens.

Outro autor cujas ideias coadunam com o âmago desta abordagem é Dardel. Para ele, a paisagem é "muito mais que uma justaposição de detalhes pitorescos [...] é um conjunto, uma convergência, um momento vivido, uma ligação interna, uma 'impressão', que une todos os elementos" (DARDEL, 2015, p. 30). Essa maneira de ver a paisagem reforça a ideia de que ela expressa essências humanas que extrapolam o que está ao alcance limitado do sentido da visão.

Nos últimos anos, como afirma Mitchell (2003 apud WYLIE, 2007, p. 191), talvez o foco mais forte das pesquisas sobre paisagem a apreenda enquanto concretização e fabricante da memória, fator que reforça a pertinência da consideração de seus aspectos simbólicos.

\section{Ao sabor das marés da (in) sustentabilidade, a conservação da natureza}

No bojo de uma crise ambiental sem precedentes na história humana, emergiram iniciativas pautadas pela necessidade de proteger a natureza das ações antrópicas que ameaçam a vida na Terra. Ao se reportarem a essa crise, Lieber e Romano-Lieber (2014, p. 765) interpretam-na enquanto crise de sentido, visto que as ameaças à vida "não vêm de forças tectônicas incontroláveis, nem mesmo de meteoros errantes, mas sim, pura e simplesmente, da prática de racionalidade humana".

No Ocidente, articulações de movimentos sociais em prol da problemática ambiental ganharam maior visibilidade mundial a partir da década de 1960, época em que o livro de Carson (2010) emergiu como um alerta em relação às consequências desastrosas da economia global de mercado sobre os sistemas ambientais.

No âmbito das discussões sobre sustentabilidade ambiental, enfatizou-se a necessidade de implementação de políticas públicas de conservação da natureza. Assim, segundo Brito (2003, p. 27), na década de 1970 "o mundo conheceu uma impressionante expansão do estabelecimento de áreas protegidas: 1.300 novos parques foram criados".

Quando se fala em gestão de áreas protegidas, convém atentar para o fato de que ela não pode ficar restrita à dimensão ambiental. Apreendê-las apenas sob esse aspecto tende a inviabilizar o alcance de seus objetivos. Nesse sentido, concorda-se com Medeiros (2003 apud MEDEIROS, 2014, p. 9), cuja definição de áreas protegidas deixa clara sua dimensão cultural: "são espaços territorialmente demarcados cuja principal função é a conservação e/ou a preservação de recursos naturais e/ ou culturais, a elas associados".

No Brasil, a maior parte das áreas protegidas integra o Sistema Nacional de Unidades de Conservação da Natureza (SNUC), instituído pela Lei n ${ }^{\circ}$ 9.985/2000 e regulamentado pelo Decreto 4.340/2002, a exemplo da categoria denominada APA. Em termos gerais, Brasil (2000) entende conservação como manejo humano da natureza, capaz de garantir a sobrevivência dos seres vivos. Segundo o SNUC, APA é

\footnotetext{
uma área em geral extensa, com um certo grau de ocupação humana, dotada de atributos abióticos, bióticos, estéticos ou culturais especialmente importantes para a qualidade de vida e o bem-estar das populações humanas, e tem como objetivos básicos proteger a diversidade biológica, disciplinar o processo de ocupação e assegurar a sustentabilidade do uso dos recursos naturais. (BRASIL, 2000)
}

A existência de legislação específica sobre conservação da natureza é relevante para o país; entretanto, não garante, por si só, a efetividade da gestão das áreas 
protegidas. Há inúmeros desafios e contradições em torno da sustentabilidade das unidades de conservação (UC) - "resultado da sobreposição de múltiplas territorialidades" (COELHO et al., 2009, p. 69) -, dentre os quais se destacam os inerentes ao uso de seus territórios e de tudo que os integra. Sobre essa questão, Diegues (1993, p. 3) assevera:

parques e reservas criados no Brasil seguem o modelo dos Estados Unidos em que, ainda em meados do século XIX existiam grandes extensões de áreas desabitadas. No Brasil, no entanto, as chamadas "áreas naturais" não são vazias, mas habitadas por povos indígenas, seringueiros, ribeirinhos, caiçaras que, por lei, são desalojados de seus territórios ancestrais ao serem decretados parques ou reservas.

\section{Ecoturismo, uma semente no turbilhão do consumo voraz dos lugares}

O turismo é um dos setores da economia que mais cresce em nível global, sendo o ecoturismo um segmento que se destaca por ter seus princípios orientados pela sustentabilidade socioambiental. Dentre seus princípios se destaca "a conservação ambiental aliada ao envolvimento das comunidades locais" (BRASIL, 2010, p. 11). Potencialidades sociais e ambientais do segmento podem ser depreendidas na concepção do Instituto Brasileiro de Turismo (Embratur):

Ecoturismo é um segmento da atividade turística que utiliza, de forma sustentável, o patrimônio natural e cultural, incentiva sua conservação e busca a formação de uma consciência ambientalista através da interpretação do ambiente, promovendo o bem-estar das populações envolvidas. (BRASIL, 1994, p. 19)

Coadunando com o conceito supracitado, a Organização Mundial do Turismo (OMT, 1999) indica que o turismo sustentável - que pode ser entendido como sinônimo de ecoturismo - é desenvolvido com base na manutenção da integridade cultural, dos processos ecológicos essenciais, da diversidade biológica e dos sistemas ambientais de suporte à vida. No mesmo sentido, a Sociedade Internacional de Ecoturismo(THE INTERNATIONAL EGOTURISM SOCIETY, 2018) o define como "responsible travel to natural areas that conserves the environment and improves the well-being oflocal people".

Convém destacar que, no Brasil, o setor passou a ter maior expressão e visibilidade a partir da
Conferência das Nações Unidas Sobre Meio Ambiente e Desenvolvimento (Eco-92), evento internacional realizado na cidade do Rio de Janeiro no ano de 1992, cuja importância para a ampliação das lutas pela sustentabilidade socioambiental é inquestionável. Dentre os desdobramentos da Eco-92, cita-se a Agenda 21, documento cujos países signatários se comprometeram a minimizar ao máximo, durante o século XXI, os impactos ambientais decorrentes de suas economias; no contexto, o ecoturismo é recomendado como atividade propícia ao alcance da meta.

Quando concebido e estruturado sob a égide da ética, o ecoturismo possibilita aliar a geração de renda à melhoria da qualidade ambiental. Ademais, por suas peculiaridades, o segmento favorece a realização de atividades relacionadas à educação ambiental, fator relevante no que tange à consecução dos objetivos de conservação da natureza. Assim como as demais atividades econômicas, o ecoturismo deve estar de acordo com o artigo 225 da Constituição Federal de 1988 (CF/1988): “Todos têm direito ao meio ambiente ecologicamente equilibrado, bem de uso comum do povo e essencial à sadia qualidade de vida, impondo-se ao Poder Público e à coletividade o dever de defendê-lo e preservá-lo para as presentes e futuras gerações" (BRASIL, 2016).

A importância do ecoturismo enquanto estratégia de conservação da natureza é reconhecida no artigo 13 da Lei Federal no 9.795/1999, que dispõe sobre a educação ambiental e institui a Política Nacional de Educação Ambiental. No contexto, a atividade, que deve ser incentivada pelo Poder Público, é concebida como algo relevante à "sensibilização da coletividade sobre as questões ambientais e à sua organização e participação na defesa da qualidade do meio ambiente" (BRASIL, 1999).

Nos termos apresentados, entende-se que o ecoturismo pode contribuir para a conservação da natureza e melhoria da qualidade de vida das populações locais, sobretudo por se basear na ideia de impacto ambiental mínimo, bem como na distribuição e participação igualitária das populações envolvidas no que tange aos benefícios socioeconômicos (MORAES; IRVING, 2013). Cumpre enfatizar: para que seja, de fato, capaz de proporcionar resultados positivos no âmbito da conservação da natureza, a atividade deve ser adequadamente planejada, organizada e adaptada à realidade dos lugares em que será realizada. 


\section{Resultados}

Na trilha dos significados, o encontro com paisagens simbólicas da APA da Região de Maracañ̃

A APA da Região de Maracanã é uma UG maranhense criada por meio do Decreto Estadual $\mathrm{n}^{\mathrm{o}}$ 12.103/1991. Localizada na porção central da Ilha do Maranhão, no município de São Luís, seu território possui características amazônicas. Segundo Farias Filho (2010), sua vegetação constitui-se de espécies vinculadas aos ecossistemas de várzeas (juçarais e buritizais), matas de sítio - onde se destacam árvores frutíferas - e, nas terras altas, espécies típicas de florestas secundárias, a exemplo dos babaçuais.

Alguns fragmentos florestais da APA são utilizados como trilhas ecológicas, fato que chama atenção para seu potencial ecoturístico. Ademais, conforme Reis et al. (2011, p. 16), "a cultura maracanaense é muito rica", composta por manifestações populares que se estendem ao longo do ano, a exemplo da Festa da Juçara, do Bumba-meu-Boi de Maracanã, do Tambor de Crioula e do Festejo de Santos Reis.

Além das manifestações mencionadas, Silva (2003) se reporta aos Festejos de Santo Antônio, São Sebastião e São Cosme e Damião, os quais também integram a identidade das comunidades tradicionais locais. Em sua abordagem, a autora apresenta pontos que auxiliam na compreensão da dimensão cultural das comunidades Maracanã e Alegria:

A Festa da Juçara é uma festa tradicional, cultural e artística, que tem por finalidade reunir pessoas [...] para acompanharem e saborearem os produtos derivados da Juçara. [...] O Bumba-meu-Boi é a segunda maior tradição que existe na comunidade de Maracanã, uma vez que os moradores participam de forma bastante descontraída, pois o seu sotaque de matraca e o som forte de seus pandeirões que arrastam multidões pelas ruas de São Luís é o que denomina este Bumba-meu-Boi como "batalhão pesado", cujo ritmo quente mexe com todo o público que acompanha a festa. [...] A Festa de Santos Reis é celebrada há mais de 60 anos com a finalidade de homenagear o nascimento de Jesus Cristo. [...] Os festejos de São Sebastião e Santo Antônio são realizados na capela de Santo Antônio, que fica na praça principal da localidade Alegria-Maracanã. (SILVA, 2003, p. 29-30)

A paisagem do barracão do Bumba-meu-Boi de Maracanã (figura 1), localizado na comunidade Maracanã, representa a força de uma das expressões populares mais conhecidas da região e do Maranhão, o Bumba-meu-Boi de Maracanã. Popularmente conhecida como Boi do Maracanã, essa manifestação cultural tem suas raízes ligadas às populações tradicionais negras que vivem há séculos no território. Ela constitui fenômeno de caráter sagrado e festivo.

Figura 1 - Paisagem do barracão do Bumba-meu-Boi do Maracanã (A), com destaque para o interior do barracão e seu patrimônio cultural (B).
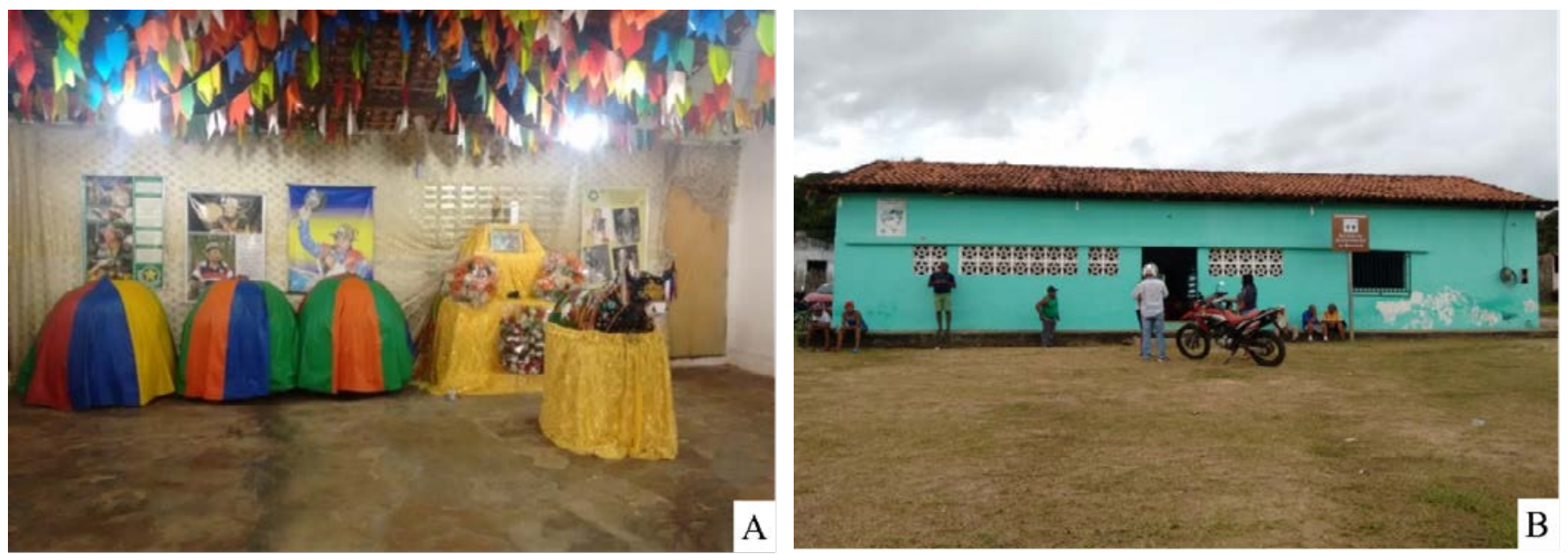

Fonte: Arquivos de pesquisa (2018). 
Essa paisagem tem seu simbolismo fortemente ligado ao mestre da cultura popular "Humberto do Maracanã, o Guriatã", como é carinhosamente conhecido Humberto Barbosa Mendes, personalidade que cumpriu o papel de amo, cantador e compositor das toadas do Boi por mais de 40 anos. O mestre faleceu no dia 19 de janeiro de 2015, aos 75 anos, mas seu legado para a cultura popular maranhense e para as comunidades da região de Maracanã permanece vivo na paisagem, na memória e no coração de seu povo. $\mathrm{O}$ excerto abaixo reflete um pouco do significado do Mestre Humberto para a cultura popular maranhense:

Nascido em 1939, Humberto Barbosa Mendes tem o hábito do boi desde menino. Figura emblemática, iniciou-se como compositor e intérprete de toadas aos 12 anos de idade. Aos 34, tornou-se Cantador Humberto do Maracanã. Hoje é reconhecido pelo Ministério da Cultura como Mestre em Cultura Popular e um dos maiores divulgadores da tradição musical maranhense [...] Cantador Humberto é o Guriatã, porta-voz do boiato, sinônimo do lugar. A lira do cantador é seu maracá de prata. A toada nasce na boca do amo e cresce forte no batalhão, gigante como as árvores do quintal. (PAULA, 2010)
No barracão, sede do Bumba-meu-Boi, acontecem atividades atinentes tanto à sua administração quanto às festividades e rituais ligados à religiosidade, aspecto marcante na vivência das pessoas que integram aquelas comunidades. A paisagem em que a sede do Boi ocupa lugar central simboliza as raízes e matrizes vinculadas à fé religiosa e seus laços fortes relacionados às festividades da realidade geográfica do Maracanã e das comunidades tradicionais filiadas àquela cultura. No entorno imediato do barracão se localizam algumas casas, pertencentes a familiares do Mestre Humberto, bem como uma escola pública e uma área verde ampla, composta por espécies nativas, onde Humberto se recolhia para meditar e buscar inspiração para compor as toadas do Boi.

A paisagem do Parque da Juçara (figura 2) possui significados ligados ao fruto da palmeira (Euterpe oleracea Mart.), a juçara, símbolo da região de Maracanã. A estrutura do referido parque destaca-se enquanto elemento central na paisagem, localizada na comunidade Alegria. Simbolicamente, essa paisagem representa geograficidades ${ }^{2}$ ligadas a uma das mais expressivas manifestações culturais daquela realidade geográfica: a Festa da Juçara.

Figura 2 - Paisagem do Parque da Juçara (A), com destaque para a 49ª Festa da Juçara (B).
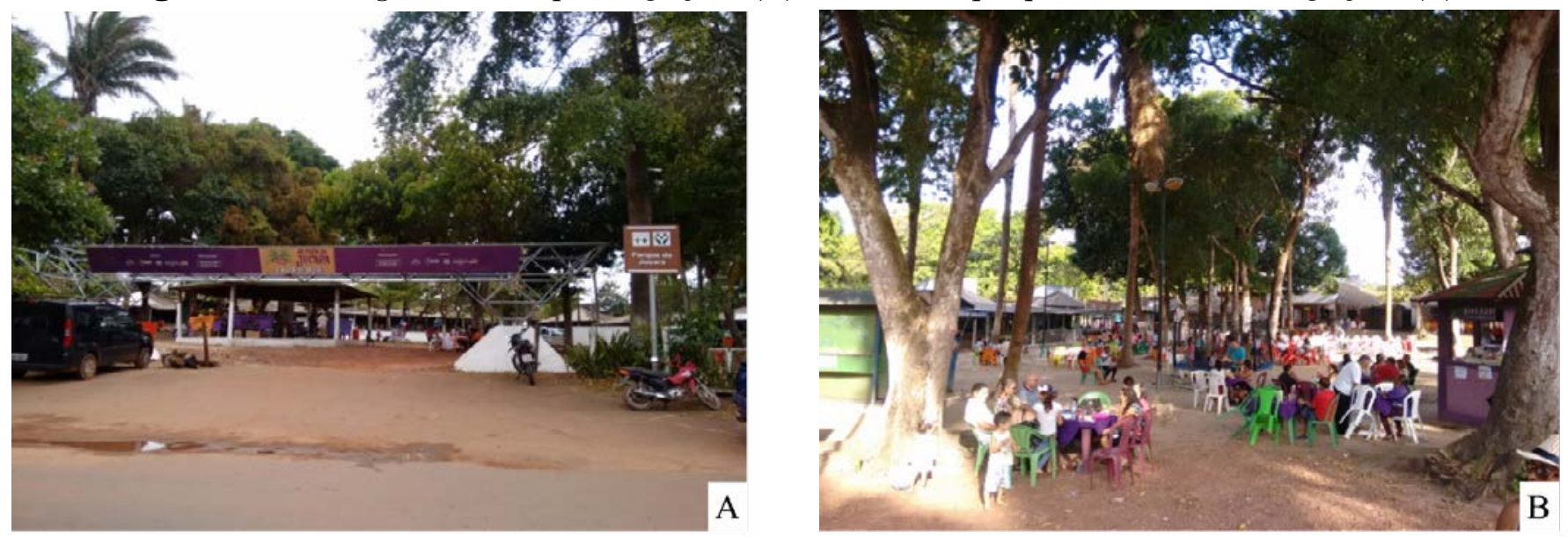

Fonte: Arquivos de pesquisa (2018).

No Parque da Juçara acontecem diversas ações comunitárias ao longo do ano, como atividades fisicas e festas.

2 De acordo com Dardel (2015), geograficidade diz respeito aos vínculos profundos entre o homem e a terra.
Cumpre notar que o parque também simboliza poder político, haja vista sua utilização por instituições sociais que tomam decisões relevantes às comunidades que o circundam, a exemplo da Associação dos Amigos do Parque da Juçara e do Conselho Consultivo da APA do Maracanã (Conam). 
Ao longo do ano, as barracas do Parque da Juçara são utilizadas principalmente como bares, restaurantes e lanchonetes comuns. Durante a Festa da Juçara, que acontece aos domingos do mês de outubro, a quantidade de pessoas ali aumenta significativamente e as barracas cumprem a função de pontos de degustação da gastronomia local. A movimentação nesse período gira em torno da comercialização da juçara e de seus derivados, especialmente o vinho da fruta, que em geral é servido gelado, acompanhado de camarão seco salgado, farinha grossa de mandioca (farinha d'água) e açúcar.

Paisagens dos brejos e juçarais (figura 3) simbolizam aquilo que as comunidades tradicionais da APA têm de mais significativo em relação aos lugares onde habitam. Todas as pessoas entrevistadas se reportam a esses sistemas ambientais enquanto elementos fundamentais à qualidade ambiental local. Ademais, fazem questão de enfatizar que os brejos e os juçarais dão vida ao Maracanã.

Figura 3 - Paisagem dos brejos e juçarais
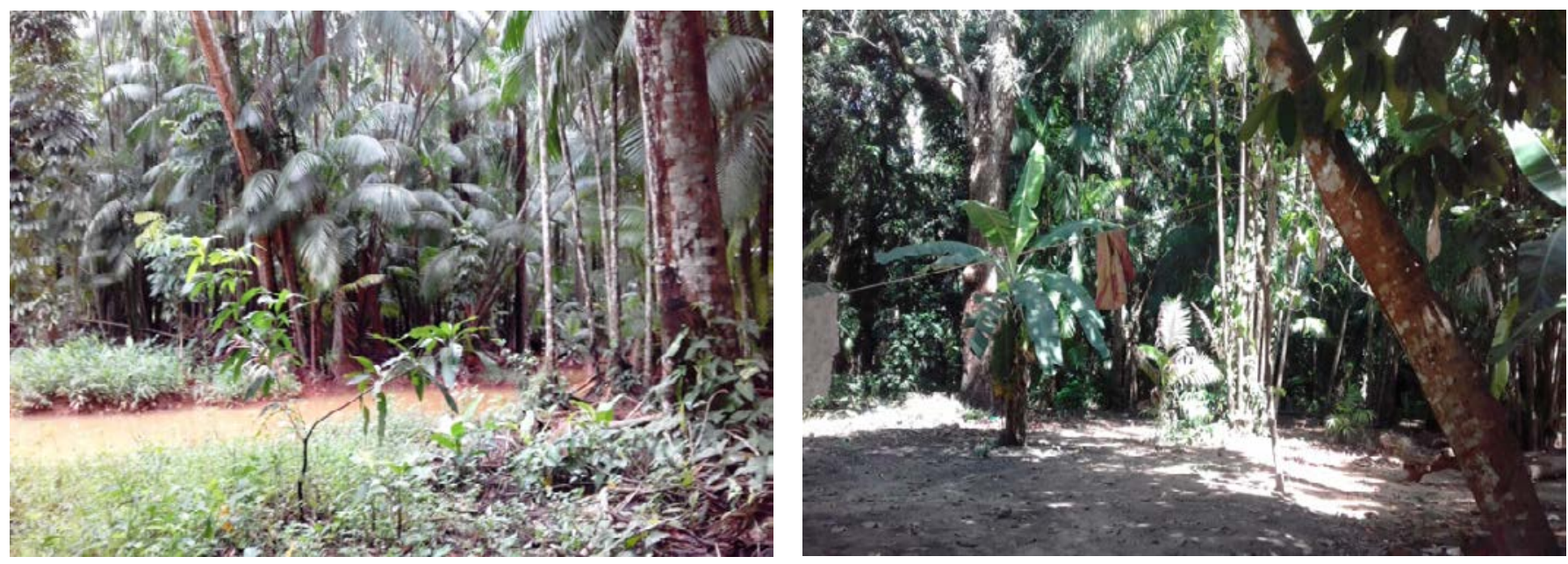

Fonte: Arquivos de pesquisa (2018).

Um dos lugares onde ainda é possível apreciar os brejos e juçarais do Maracanã é o Bosque Ecológico do Cesco, mantido pelo Centro Educacional "Sagrados Corações" (Cesco), escola comunitária localizada na comunidade Alegria, cuja representante, a professora Maria Carminda Arruda Guimarães, se destaca enquanto liderança local engajada na luta pela conservação da natureza do Maracanã.

Algo muito significativo na APA do Maracanã diz respeito às paisagens do sincretismo religioso e dos festejos a ele associados. Dentre as religiões mais expressivas se encontra a umbanda, âmbito em que se realiza, por exemplo, o festejo do encantado ${ }^{3}$ Manezinho Légua Boji Buá, com participação das rezadeiras católicas, que rezam uma ladainha no início da celebração (figura 4).

3 Encantados são seres mais que humanos que, no passado, foram pessoas. Sua mudança de estatuto aconteceu diante do seu desaparecimento (sem morte), momento em que se encantaram, passando a viver em um entre mundo de localização não exata chamado de Encantaria (AHLERT, 2016, p. 1).
O Festejo de Santos Reis ocorre sempre no mês de janeiro, entre os dias 5 e 6 . Existem três grandes festas de Reis no Maracanã: Reis das Nuvens, Reis da Sempre Viva e Reis do Alecrim. A festa dos Reis das Nuvens (figura 5) é realizada no sítio da família da líder comunitária Flávia de Sá, situado à rua Menino Jesus, na comunidade Alegria. A paisagem constitui-se de elementos da umbanda e do catolicismo.

No sítio dos Reis das Nuvens, a família realiza, no dia 20 de novembro (Dia Nacional da Umbanda), uma Roda de Tambor de Crioula (figura 6) em homenagem a São Benedito (santo católico) e a entidades da umbanda, como Preto Velho. Geralmente iniciadas nas comunidades locais por meio de uma ladainha, manifestações culturais como essa são realizadas para pagar promessas por graças alcançadas. A beleza dos ritos e da dança impressiona, assim como a alegria e gentileza dos anfitriões ao acolher as pessoas que chegam para participar. 
Figura 4 - Paisagem do sincretismo religioso, com destaque para o festejo do encantado Manezinho Légua Boji Buá, na Casa Remanescente da Luz
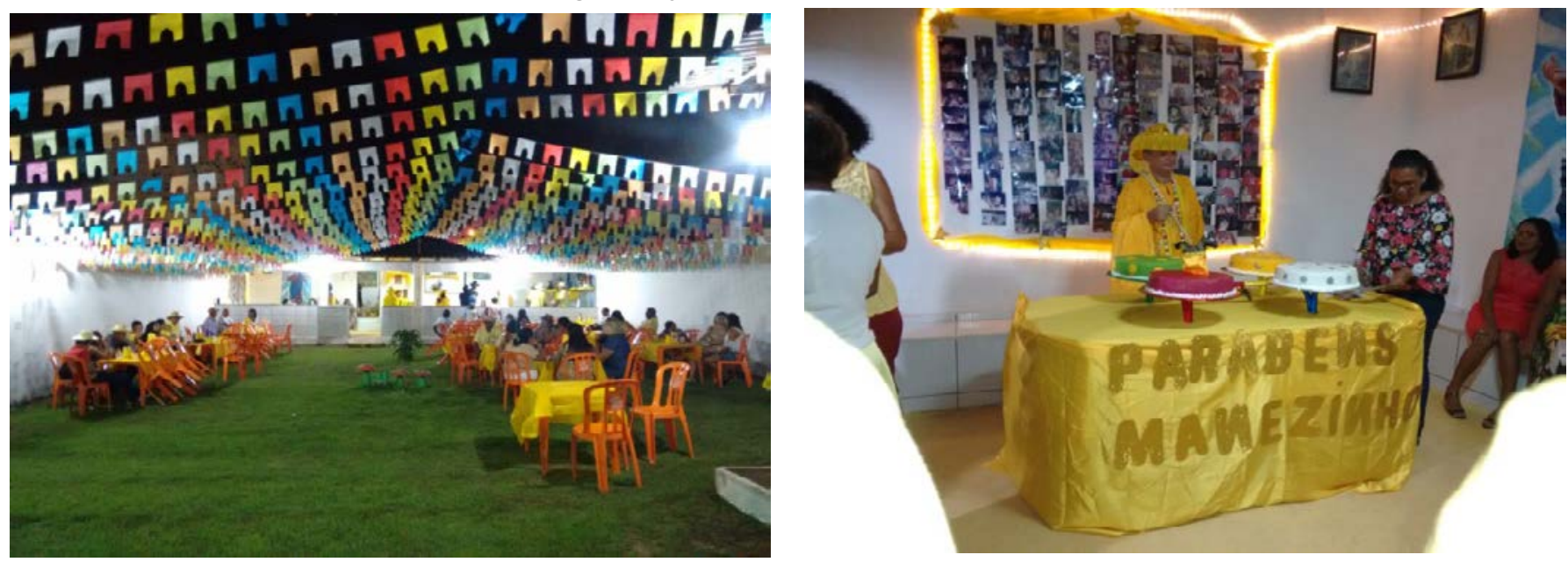

Fonte: Arquivos de pesquisa (2018).

Figura 5 - Paisagem do Festejo de Reis, durante a Festa do Rei das Nuvens
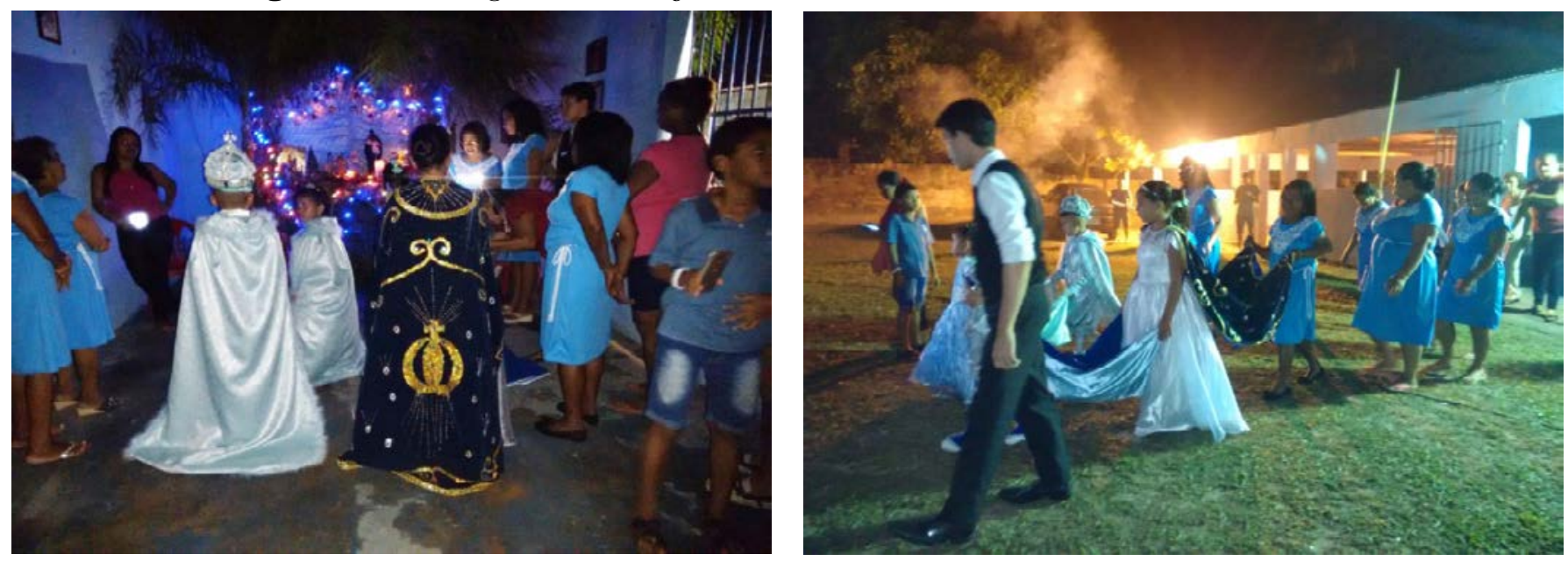

Fonte: Arquivos de pesquisa (2018).

Figura 6 - Paisagem do Tambor de Crioula, no sítio do Reis das Nuvens
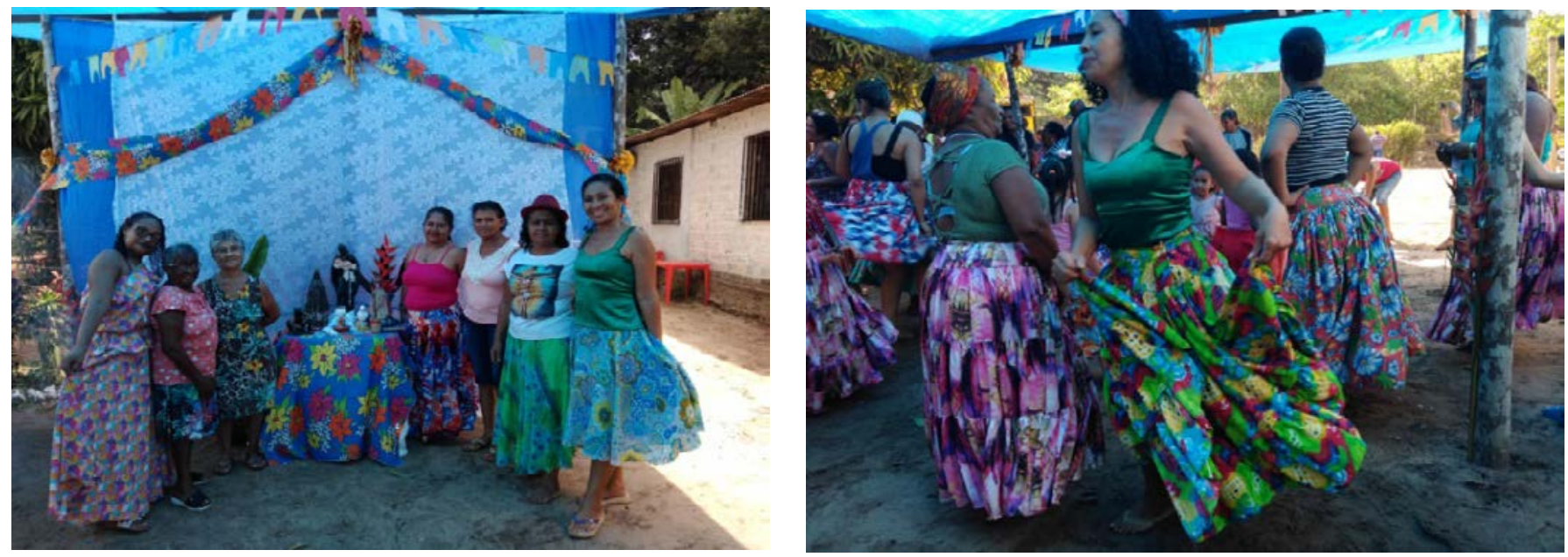

Fonte: Arquivos de pesquisa (2018). 


\section{CONSIDERAÇÕES FINAIS}

Diante dos resultados obtidos foi possível evidenciar a existência de paisagens simbólicas relevantes para o desenvolvimento do ecoturismo na APA do Maracanã. Adentrar o mundo dos significados das paisagens pode ser extremamente interessante quando se pretende realizar atividades como o ecoturismo.

Por se tratar de uma APA, tipo de área protegida onde é permitido o uso direto de recursos naturais desde que cumpridas as exigências da legislação e dos documentos técnicos que direcionam a gestão da UC, como o Plano de Manejo -, o ecoturismo pode ser visto enquanto possibilidade de compatibilização entre geração de renda, inclusão social e os objetivos da UC.

A articulação entre as diversas dimensões que compõem o universo da APA do Maracanã, especialmente os atinentes aos seus atributos naturais e culturais, integrantes das paisagens simbólicas, constitui importante estratégia voltada para o reconhecimento e valorização das potencialidades ecoturísticas dos lugares que integram o território em questão.

Ao longo da aplicação das entrevistas e dos diálogos informais durante os eventos nas comunidades, foi possível perceber o desejo de que a região de Maracanã seja alvo de políticas públicas capazes de melhorar as condições de vida das pessoas que vivem ali, assim como proteger os sistemas ambientais locais. Este anseio é passível de ser transformado em realidade, tão logo haja interesse do Poder Público em incentivar e fomentar, por exemplo, o aproveitamento do potencial ecoturístico das paisagens simbólicas da APA do Maracanã.

\section{Agradecimentos}

Agradecemos a todas as pessoas e instituições que têm contribuído para a realização da pesquisa de que trata este artigo, especialmente: às comunidades da APA da Região de Maracanã, representadas pelas senhoras Flávia de Sá e Odelina Ferraz e pelo senhor Fábio Marlos de Sá, à Universidade Federal do Maranhão, à Universidade Estadual Paulista, à Fundação de Amparo à Pesquisa e ao Desenvolvimento Científico e Tecnológico do Maranhão, ao Conam, à Secretaria de Estado de Meio Ambiente e dos Recursos Naturais do Maranhão e ao Cesco.

\section{REFERÊNCIAS}

AHLERT, M. "A família de Légua tá toda na eira": tramas de parentesco nas relações entre pessoas e encantados. In: REUNIÃO BRASILEIRA DE ANTROPOLOGIA, 30., 2016, João Pessoa. Anais [...]. João Pessoa: Abant, 2016. p. 1-13. Disponível em: http://bit.ly/2TE6gR1. Acesso em: 20 nov. 2018.

BERQUE, A. Paisagem-marca, paisagem-matriz: elementos da problemática para uma geografia cultural. In: CORRÊA, R. L.; ROSENDAHL, Z. (org.). Paisagem, tempo e cultura. 2. ed. Rio de Janeiro: EdUERJ, 2004. p. 84-91.

BERTRAND, G. Paisagem e Geografia Física Global: esboço metodológico. RA'EGA, Guritiba, n. 8, p. 141-152, 2004.

BESSE, J-M. Ver a terra: seis ensaios sobre a paisagem e a geografia. Tradução: Vladimir Bartalini. São Paulo: Perspectiva, 2014. (Coleção Estudos, 230).

BONNEMAISON, J. Viagem em torno do território. In: CORRÊA, R. L.; ROSENDAHL, Z. Geografia cultural: um século. Rio de Janeiro: EdUERJ, 2002. p. 88-131.

BRASIL. Diretrizes para uma política nacional de ecoturismo. Coordenação: Silvio Magalhães Barros e Denise Hamú M. de La Penha. Brasília, DF: Embratur, 1994.

BRASIL Lei n ${ }^{\circ}$ 9.795, de 27 de abril de 1999. Dispõe sobre a educação ambiental, institui a Política Nacional de Educação Ambiental e dá outras providências. Diário Oficial da União: Seção 1, Brasília, DF, ano 111, n. 79, p. 1, 28 abr. 1999.

BRASIL. Lei n ${ }^{\circ}$ 9.985, de 18 de julho de 2000. Regulamenta o Art. $225, \S 1^{\circ}$, inciso I, II, III, VII da Constituição Federal, institui o Sistema Nacional de Unidades de Conservação da Natureza e dá outras providências. Diário Oficial da União: Seção 1, Brasília, DF, p. 1, 19 jul. 2000. 
BRASIL. Ministério do Turismo. Ecoturismo: orientações básicas. 2. ed. Brasília, DF: Ministério do Turismo, 2010.

BRASIL. Constituição da República Federativa do Brasil. Brasília, DF: 2016, Senado Federal.

BRITO, M. C. W. Unidades de conservação: intenções e resultados. 2. ed. São Paulo: Annablume: Fapesp, 2003.

CARSON, R. Primavera silenciosa. Tradução: Claudia Sant'Anna Martins. São Paulo: Gaia, 2010.

COELHO, M. G. N.; GUNHA, L. H.; MONTEIRO, M. A. Unidades de Conservação: populações, recursos e territórios. Abordagem da Geografia e da Ecologia Política. In: GUERRA, A. J. T.; COELHO, M. C. N. (org.). Unidades de conservação: abordagens e características geográficas. Rio de Janeiro: Bertrand Brasil, 2009. p. 67-111.

CORRÊA, R. L.; ROSENDAHL, Z. Apresentando leituras sobre paisagem, tempo e cultura. In: CORRÊA, R. L.; ROSENDAHL, Z. (org.). Paisagem, tempo e cultura. 2. ed. Rio de Janeiro: EdUERJ, 2004. p. 7-11.

COSGROVE, D. E. Social formation and symbolic landscape. 2. ed. Madison: The University of Wisconsin Press, 1998.

COSGROVE, D. E. A geografia está em toda parte: cultura e simbolismo nas paisagens humanas. Tradução: Olivia B. Lima da Silva. In: CORRÊA, R. L.; ROSENDAHL, Z. (org.). Paisagem, tempo e cultura. 2. ed. Rio de Janeiro: EdUERJ, 2004, p. 92-123.

DARDEL, E. O homem e a terra: natureza da realidade geográfica. Tradução: Werther Holzer. São Paulo. Perspectiva, 2015.

DIEGUES, A. C. S. Populações tradicionais em unidades de conservação: o mito da natureza intocada. São Paulo: USP, 1993. (Série Documentos e Relatórios de Pesquisa, 1).
FARIAS FILHO, M. S. Caracterização geoambiental da Área de Proteção Ambiental da Região de Maracanã, São Luís-MA. In: FORTES, R. (org.). Área de Proteção Ambiental do Maracanã: subsídios ao manejo e à educação ambiental. São Luís: FAPEMA: Café \& Lápis, 2010. p. 15-39.

HOLZER, W. Uma discussão fenomenológica sobre os conceitos de paisagem e lugar, território e meio ambiente. TERRITÓRIO, Rio de Janeiro, ano II, n. 3, p. 77-85, jul./dez. 1997.

LIEBER, R. R.; ROMANO-LIEBER, N. S. A sustentabilidade é sustentável? Educando com o conceito de risco. In: PHILIPPIJR., A.; PELICIONI, M. C. F. (ed.). Educação ambiental e sustentabilidade. 2.ed. Barueri: Manole, 2014. p. 765-786. (Coleção Ambiental, v. 14).

MEDEIROS, R. Evolução das tipologias e categorias de áreas protegidas no Brasil. In: LIMA, G. S.; ALMEIDA, M. P.; RIBEIRO, G. A. (org.). Manejo e conservação de áreas protegidas. Viçosa: UFV, 2014. p. 9-39.

MENDONÇA, F. Geografia física: ciência humana? 7. ed. São Paulo: Contexto, 2001. (Coleção Repensando a Geografia).

MORAES, E. A.; IRVING, M. A. Ecoturismo: encontros e desencontros na Reserva Extrativista do Cazumbá-Iracema (AC). Revista Brasileira de Ecoturismo, São Paulo, v. 6, n. 3, p. 738-757, ago./ out. 2013.

NOGUÉ, J. (ed.). La construcción social del paisaje. Madrid: Biblioteca Nueva, 2016.

ORGANIZAÇÃO MUNDIAL DO TURISMO. Gódigo Mundial de Ética do Turismo. Santiago do Chile: OMT, 1999.

PAULA, J. Vida de cantador: Humberto do Maracanã. Cultura Brasil, São Paulo, 22 jun. 2010. Veredas. Disponível em: http://bit.ly/2Q5WN2N. Acesso em: 16 dez. 2018. 
REIS, R.J.; GALVÃO, A. A. S.; SOARES, J. M. S. Cartilha

da APA do Maracanã. São Luís: Eduema, 2011.

RISSO, L. C. Paisagens e cultura: uma reflexão teórica a partir do estudo de uma comunidade indígena amazônica. Espaço e Cultura, Rio de Janeiro, n. 23, p. 67-76, jan./jun. 2008.

SAUER, O. C. A morfologia da paisagem. In: CORREAA, R. L.; ROSENDAHL, Z. (org.). Paisagem, tempo e cultura. 2. ed. Rio de Janeiro: EdUERJ, 2004, p. 12-74.
SILVA, L. L. A importância sócio-ambiental da Festa da Juçara para a comunidade de Maracanã, São Luís - MA. 2003. Trabalho de Conclusão de Curso (Graduação em Geografia) Universidade Federal do Maranhão, São Luís, 2003.

THE INTERNATIONAL ECOTURISM SOCIETY. TIES announces ecotourism principles revision. Washington, DC: TIES, 7 jan. 2015. Disponível em: http://bit.ly/2xaWE7H. Acesso em: 27 set. 2018.

WYLIE, J. Landscape. London: Routledge, 2007. 